\title{
Effects of Radiotherapy in the treatment of multiple myeloma: a retrospective analysis of a Single Institution
}

Christiane Matuschek ${ }^{1}$, Thomas A Ochtrop ${ }^{1}$, Edwin Bölke ${ }^{1 *}$, Ute Ganswindt ${ }^{8}$, Roland Fenk², Stephan Gripp ${ }^{1}$, Patric Kröpil ${ }^{3}$, Peter Arne Gerber ${ }^{4}$, Kai Kammers ${ }^{5}$, Jackson Hamilton ${ }^{6}$, Klaus Orth ${ }^{7}$ and Wilfried Budach ${ }^{1}$

\begin{abstract}
Background: Palliative irradiation of osteolytic lesions is a considerable component in the treatment for patients with multiple myeloma. In this study, we analyzed the efficacy of irradiation in these patients.

Patients and methods: We retrospectively analyzed 153 patients with multiple myeloma who were admitted to our department between 1989 and 2013. According to the staging system of Durie \& Salmon 116 patients were classified as stage III. 107/153 patients were treated with radiotherapy of at least one and up to 6 bony lesions at different times. In order to evaluate the effect of local radiotherapy on pain relief and bone recalcification a uni- and multivariate analysis was performed using a binary logistic regression model to correct for multiple measurements. Complete information on dose, fractionation and volume of radiotherapy was available from 81 patients treated in 136 target volumes for pain relief, and from 69 patients treated in 108 target volumes for recalcification. Total radiation doses varied between 8 Gy to 50 Gy (median dose 25 Gy in 2.5 Gy fractions, 5 times a week).

Results: Radiotherapy resulted in complete local pain relief in 31\% and partial local pain relief in 54\% of the patients. In the univariate analysis, higher total radiation doses $(p=0.023)$ and higher age $(p=0.014)$ at the time of radiotherapy were significantly associated with a higher likelihood of pain relief, whereas no significant association was detected for concurrent systemic treatment, type and stage of myeloma and location of bone lesions. The same variables were independent predictors for pain relief in the multivariate analysis. Recalcification was observed in $48 \%$ of irradiated bone lesions. In the uni- and multivariate analysis higher radiation doses were significantly associated $(p=0.048)$ with an increased likelihood of recalcification. Side effects of radiotherapy were generally mild.

Conclusions: Higher total biological radiation doses were associated with better pain relief and recalcification in this retrospective evaluation of multiple myeloma patients. In addition, in the elderly the therapeutic measures appear to develop a better analgesic effect.
\end{abstract}

Keywords: Multiple myeloma, Plasmocytoma, Radiotherapy, Radiation therapy, Analgesic effect, Recalcification, Side effects

\footnotetext{
* Correspondence: boelke@med.uni-duesseldorf.de

'Department of Radiation Oncology, Faculty of Medicine,

Heinrich-Heine-University Düsseldorf, Moorenstraße 5, 40225 Düsseldorf,

Germany

Full list of author information is available at the end of the article
} 


\section{Introduction}

Multiple myeloma is a cancer of plasma cells, clinically characterized by recurrent bone pain, soft tissue masses, anemia, infections, neurological symptoms, hypercalcemia and renal failure. Modern treatment of multiple myeloma consists of a combination of different treatment approaches including high-dose chemotherapy followed by autologous stem cell transplantation, immunomodulatory drugs, such as thalidomide, lenalidomide, pomalidomide and proteasome inhibitors, such as bortezomib, carfilzomib or MLN9708. With these novel combinations the median overall survival of patients with multiple myeloma approaches $50 \%$ and better, 10 years after first diagnosis [1]. Although these are rare tumors they are the major causes of bone involvement [2]. Osteolytic process leads to an increased risk of pathologic fracture and severe pain with negative impact on quality of life.

Palliative irradiation of painful osteolytic processes is an important component in the treatment of multiple myeloma [3]. The efficacy of different radiation regimens in the palliative treatment of bone metastases from solid tumors has been tested in a number of trials [4-7]. In some trials a small number of patients with multiple myeloma were included, but in most cases no subgroup analysis was presented [7]. As a consequence, different consultants used different radiation regimens ranging from $1 \times 8$ Gy to $20 \times 2$ Gy in the palliative treatment of painful bone lesions and in patients with multiple myeloma. In our retrospective study, we analyzed the effects of these different radiation regimes on pain relief and recalcification.

\section{Materials and methods}

We retrospectively collected data from the records of patients with the diagnosis of multiple myeloma treated by the Departments of Radiation Oncology and HematoOncology at the Heinrich-Heine-University in Düsseldorf, Germany, from 1989 to 2013. Patients were excluded, if their documentation lacked accurate information or they suffered from another acutely life threatening neoplasm. 153 patients were identified of whom 107 underwent radiotherapy and of whom 46 patients did not receive radiotherapy at any time. Patients' characteristics are displayed in Tables 1 and 2. Complete information on dose, fractionation and volume of radiotherapy was available in 99 patients. Patients were followed until 2013. For the end point pain relief after radiotherapy, valid data from $81 \mathrm{pa}-$ tients treated in 136 targeted volumes were available (1-6 target volumes per patient, median: 1 volume). For the end point recalcification after radiotherapy, valid data of 69 patients treated in 108 targeted volumes were available (1-5 target volumes per patient, median: 1 volume). Fractionated radiotherapy was administered in $4-5$ fractions
Table 1 Patients' characteristics

\begin{tabular}{|c|c|c|}
\hline Characteristics & & $\mathrm{N}$ \\
\hline \multirow[t]{3}{*}{ Irradiation } & Irradiated Pat. & 107 (70\%) \\
\hline & Target Vol. & 202 \\
\hline & No Radiation & $46(30 \%)$ \\
\hline Status & Alive & $77(50 \%)$ \\
\hline \multirow[t]{2}{*}{ Sex } & Male & $86(56 \%)$ \\
\hline & Female & $67(44 \%)$ \\
\hline Age (years) & Range 30-87 & 59 median \\
\hline \multirow[t]{7}{*}{ Classification } & IgG kappa & 59 (39\%) \\
\hline & IgG lambda & $25(16 \%)$ \\
\hline & IgA kappa & $21(14 \%)$ \\
\hline & IgA lambda & $15(10 \%)$ \\
\hline & Kappa & $15(10 \%)$ \\
\hline & Lambda & $05(03 \%)$ \\
\hline & Diverse & $13(08 \%)$ \\
\hline Stage at first diagnosis & 1 & $21(14 \%)$ \\
\hline \multirow[t]{3}{*}{ (Durie\&Salmon [8]) } & $\|$ & $16(10 \%)$ \\
\hline & $\| I \mid A$ & $99(65 \%)$ \\
\hline & III B & $17(11 \%)$ \\
\hline \multirow[t]{7}{*}{ Radiation dose (Gy) } & 08 & $02(01 \%)$ \\
\hline & 20 & $63(31 \%)$ \\
\hline & 25 & $36(18 \%)$ \\
\hline & 30 & $26(13 \%)$ \\
\hline & 36 & $38(19 \%)$ \\
\hline & 40 & $26(13 \%)$ \\
\hline & Diverse & $11(05 \%)$ \\
\hline $\begin{array}{l}\text { Simultaneous } \\
\text { chemotherapy }\end{array}$ & $\begin{array}{l}\text { (with statement about } \\
\text { analgesia) }\end{array}$ & $108(73)$ \\
\hline Surgical intervention & & $29(20)$ \\
\hline
\end{tabular}

$\mathrm{n}=$ number of patients, Stage $=$ Durie and Salmon.

per week. Most target volumes were irradiated with 6-25 MV photons; a minority of 29 target volumes was treated with a cobalt-60 device. External beam radiation was delivered via one to three or greater external beams. Indications for radiotherapy were osseous pain, pathologic fractures, or neurological symptoms related to osteolytic lesions. On average, radiotherapy was performed 4 months after initial diagnosis, ranging from 1 to 179 months. Systemic therapy was given simultaneously to 108 of the irradiated patients (Table 1). Surgical intervention in the area of irradiation was performed in 46 patients (19 at peripheral fractures and 27 vertebral operations, e.g. 9 vertebroplastics, 11 laminectomies and 7 other procedures). The follow-up was 1 up to 22 years after completing radiotherapy treatment in different time intervals.

Analgesic effects during the first year after radiotherapy were retrospectively extracted from the patient's files using a Likert scale [9] for pain. The analgesic effect was 
Table 2 Anatomic location of irradiated osteolyses

\begin{tabular}{|c|c|c|c|c|c|c|}
\hline \multirow[t]{2}{*}{ Location } & & \multirow[b]{2}{*}{ No. } & \multicolumn{3}{|c|}{ Analgesia \% } & \multirow{2}{*}{$\begin{array}{l}\text { Side Effects \% } \\
\text { (Level I-II) }\end{array}$} \\
\hline & & & Total & Full & $\overline{\text { Partial }}$ & \\
\hline \multirow[t]{5}{*}{ Spine } & Thoracic Spine (TS) & 32 & 84 & 38 & 47 & 20 \\
\hline & Lumbar Spine (LS) & 12 & 100 & 25 & 75 & 25 \\
\hline & Cervical Spine (CS) & 8 & 75 & 38 & 37 & 13 \\
\hline & $\mathrm{CS} / \mathrm{TS}$ & 4 & 100 & 100 & 0 & 0 \\
\hline & $\mathrm{TS} / \mathrm{LS}$ & 11 & 79 & 45 & 54 & 20 \\
\hline \multirow[t]{2}{*}{ Extremities } & Superior & 12 & 91 & 16 & 75 & 16 \\
\hline & Inferior & 15 & 80 & 0 & 80 & 8 \\
\hline Trunk & Pelvis/Hip & 24 & 87 & 41 & 45 & 19 \\
\hline \multirow[t]{4}{*}{ Others } & Sternum & 3 & 100 & 10 & 90 & 25 \\
\hline & Ribs & 9 & 55 & 11 & 44 & 11 \\
\hline & Clivus & 2 & 100 & 50 & 50 & 0 \\
\hline & Skull & 10 & 70 & 10 & 60 & 50 \\
\hline Extramedullary tumor & & 10 & 90 & 30 & 60 & 21 \\
\hline Other tocations/missing data & & 18 & & & & \\
\hline
\end{tabular}

Level (RTOG).

categorized to complete pain relief, partial pain relief and no pain relief. For the statistical analysis a binary outcome was used taking together partial to complete pain relief to one category.

Recalcification was based on assessment of tumor remission by World Health Organization (WHO) criteria and divided into 4 categories of skeletal metastases [10]: complete remission (CR, for at least 4 weeks), partial remission (PR, size reduction and recalcification), no change (status idem), and progressive disease (PD), which was defined as a size increase of more than 20\% [11]. Recalcification was measured with the help of a computed tomography (CT) [12]. Degree of recalcification was based on a comparison of pre-treatment and post-treatment (at least 3 months to 1 year after irradiation) radiographs (CT and/or MRI) using ROI (Region Of Interest) and diameter measurement, as well as manifest sclerosis. For the statistical analysis a binary outcome was used taking partial to complete remission to one category and no change and progression to the other category.

In addition, available information in radiation related side effects were recorded and categorized by the criteria of Radiation Therapy Oncology Group (RTOG) [13]. Overall survival was also assessed up to the year of 2013 for all patients.

\section{Statistical analysis}

For statistical analysis, SPSS 21.0 was used. Frequencies were determined by descriptive analyses. P-values $<0.05$ were regarded as statistically significant. Overall survival was estimated by the Kaplan-Meier method and differences of subgroups were tested by the log-rank test.
In irradiated patients, the effects of radiotherapy on the end points pain relief and recalcification were assessed by using an uni- and multivariate binary logistic regression model that incorporates adjustments for repeated measurements in the same patient (GENLIN procedure, SPSS 21.0). Radiation dose and fractionation was normalized according to the linear quadratic model [14] assuming no relevant repopulation to 2 Gy equivalence doses for $\alpha / \beta$-values of 2 Gy and $10 \mathrm{~Gy}$. The Wald test was employed to assess the significance of tested variables and for exclusion from the model in the stepwise backward procedure in the multivariate analysis. Since 2 Gy equivalence doses using $\alpha / \beta$-values of 2 Gy and 10 Gy were highly co-correlated, the initial model of the multivariate analysis included the 2 Gy equivalence dose using an $\alpha / \beta$-values $10 \mathrm{~Gy}$ as dose variable only, which was the better predictor of dose response for both end points (pain relief and recalcification).

\section{Results}

\section{Analgesia}

Treatment-related analgesia occurred during or at the end of the course of radiotherapy. In follow-up records we noticed pain relief in $85 \%$ of the patients which lasted for at least 1 year after radiotherapy. We evaluated 136 target volumes in 81 patients in terms of analgesia. In $85 \%$ of the treated patients, an analgesic effect was achieved by irradiation of painful areas. Patients reported complete and partial pain relief in 31\% and 54\% of the treated lesions, respectively (no change $=12 \%$, progression $=3 \%$ ). In the uni- and multivariate binary logistic regression analysis improved pain relief (complete/ 
partial) was significantly associated with higher total 2 Gy-equivalence doses $(\alpha / \beta=10$ Gy) and higher patient's age at the time of radiotherapy, whereas all other tested factors were not associated with pain relief (Table 3). According to the model, an increase from 20 to $30 \mathrm{~Gy}$ total dose (2 Gy equivalence $(\alpha / \beta=10 \mathrm{~Gy})$ resulted in a $12 \%$ higher likelihood of complete or partial pain relief (Figure 1). Also, a 70 year old patient showed a $13 \%$ greater chance of complete or partial pain relief after radiotherapy compared to a 50 year old patient (Figure 2). Furthermore we found no correlation between pain relief and recalcification (Chi square test, $\mathrm{p}=0.35$ ).

\section{Recalcification}

The effect of radiotherapy in 108 target volumes of 69 patients were evaluated for change in calcification based on pre- and post-treatment radiographs. Overall, recalcification was observed in $48 \%$ of the treated bone lesions. In $23 \%$ of cases full recalcification and in $25 \%$ partial recalcification was observed. No change of calcification could be documented in $42 \%$ of the bone lesions, and $10 \%$ of the patients developed progression of osteolytic lesions. In the uni- and multivariate binary logistic regression analysis higher total (2 Gy-equivalence) doses $(\alpha / \beta=10 \mathrm{~Gy})$ were significantly associated with better recalcification (complete/partial), whereas all other tested factors were not associated with better recalcification (Tables 2,3,4). According to the model, an increase from 20 to $30 \mathrm{~Gy}$ total dose ( 2 Gy equivalence dose, $\alpha / \beta=10$ Gy) resulted in a $12 \%$ higher likelihood $(p=0.048)$ of complete or partial recalcification (Figure 3 ).

\section{Side effects}

In this retrospectively evaluated cohort, 40 of 107 patients (37\%) suffered from side effects related to radiotherapy. Of these, $50 \%$ showed grade 1 , and $47.2 \%$ grade 2 side effects. One patient suffered from dysphagia (grade 3 adverse event). No case of radiation induced myelopathy was observed clinically.

\section{Survival}

Median overall survival was 89.1 months for the whole cohort. Patients requiring palliative radiotherapy for painful bone involvement had a worse prognosis than patients without these findings (Figure 4) (median survival time 77 vs. 165 months, $\mathrm{p}=0.233$ ). But there was no significant difference.

\section{Discussion}

\section{Pain relief}

Osteolytic lesions and bone pain is a common symptom in patients with multiple myeloma and present at the time of first diagnosis in 70\% of cases [5]. Larger osteolytic lesions are frequently associated with pain and the risk of fracture. Accordingly, radiotherapy in addition to systemic treatment is typically administered in these

Table 3 Univariate and multivariate analysis of analgesic effect and recalcification of patients undergoing radiotherapy

\begin{tabular}{|c|c|c|c|c|c|}
\hline End point & Variable & $\operatorname{Exp}(B)$ & Lower $95 \% \mathrm{CL}$ of $\operatorname{Exp}(\mathrm{B})$ & Upper 95\% CL Exp (B) & p-value \\
\hline Pain relief & $\alpha / \beta=2$ Gy & 1.072 & 1.002 & 1.146 & $0.043^{*}$ \\
\hline Pain relief & $a / \beta=10$ Gy & 1.087 & 1.012 & 1.168 & $0.023^{*}$ \\
\hline Pain relief & target volume & 1.088 & 1.015 & 1.167 & $0.018^{*}$ \\
\hline Pain relief & age at RT & 1.062 & 1.012 & 1.114 & $0.014^{*}$ \\
\hline Pain relief & gender & 1.432 & 0.469 & 4.376 & 0.529 \\
\hline Pain relief & Typ kappa & 2.572 & 0.685 & 9.654 & 0.162 \\
\hline Pain relief & Typ lambda & 0.360 & 0.077 & 1.676 & 0.193 \\
\hline Pain relief & $\lg G$ & 1.228 & 0.405 & 3.702 & 0.717 \\
\hline Pain relief & $\lg A$ & 1.91 & 0.253 & 3.312 & 0.893 \\
\hline Pain relief & concurrent systemic treatment (yes/no) & 1.285 & 0.241 & 6.863 & 0.769 \\
\hline Recalcification & $a / \beta=2$ Gy & 1.043 & 0.996 & 1.091 & 0.074 \\
\hline Recalcification & $a / \beta=10 \mathrm{~Gy}$ & 1.050 & 1.000 & 1.101 & $0.048^{*}$ \\
\hline Recalcification & target volume & 1.049 & 1.000 & 1.100 & $0.050^{*}$ \\
\hline Recalcification & age at RT & 1.023 & 0.983 & 1.064 & 0.272 \\
\hline \multicolumn{6}{|c|}{ Multivariate analysis } \\
\hline Pain relief & $a / \beta=10$ Gy & 1.087 & 1.007 & 1.172 & $0.032^{*}$ \\
\hline Pain relief & age at RT & 1.066 & 1.008 & 1.127 & $0.025^{*}$ \\
\hline Recalcification & $a / \beta=10 \mathrm{~Gy}$ & 1.050 & 1.000 & 1.101 & $0.048^{*}$ \\
\hline
\end{tabular}

CL Confidence Level, *significance. Univariate Analysis. 


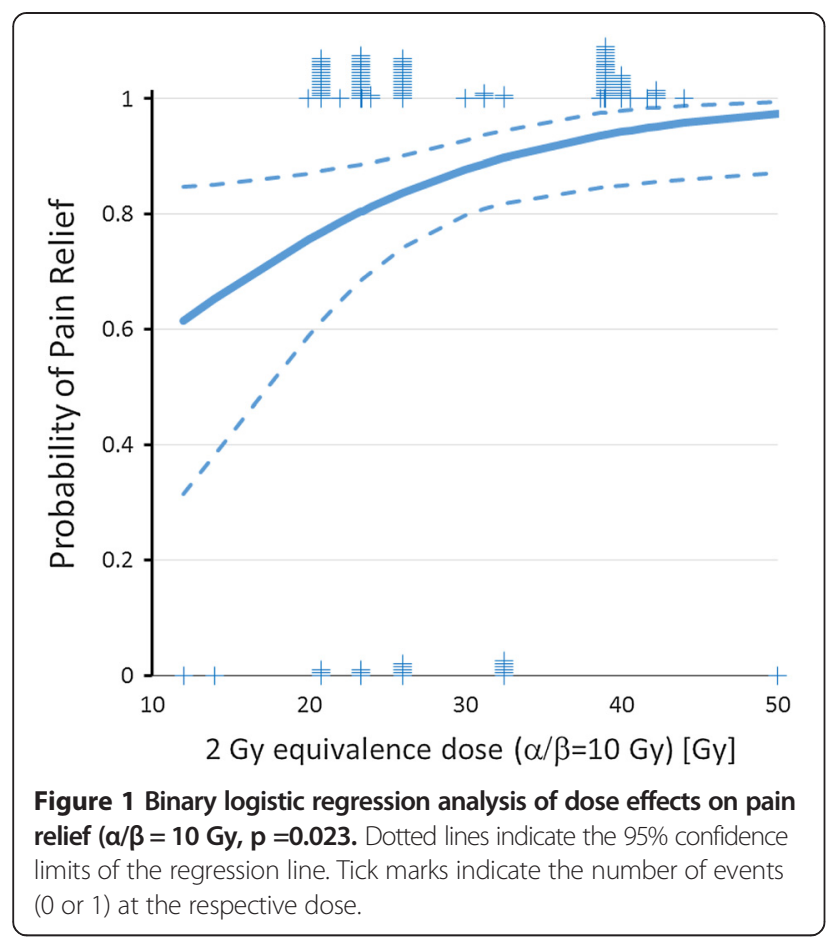

situations and is frequently associated with rapid pain relief. Bone disease remains complex and is caused by the production of the osteoclast stimulating enzymes [15]. The inhibition of pain mediators and the shrinkage of the tumor are thought to be the main mechanisms of analgesic effects derived from irradiation. The often rapid analgesic effect of irradiation is not completely

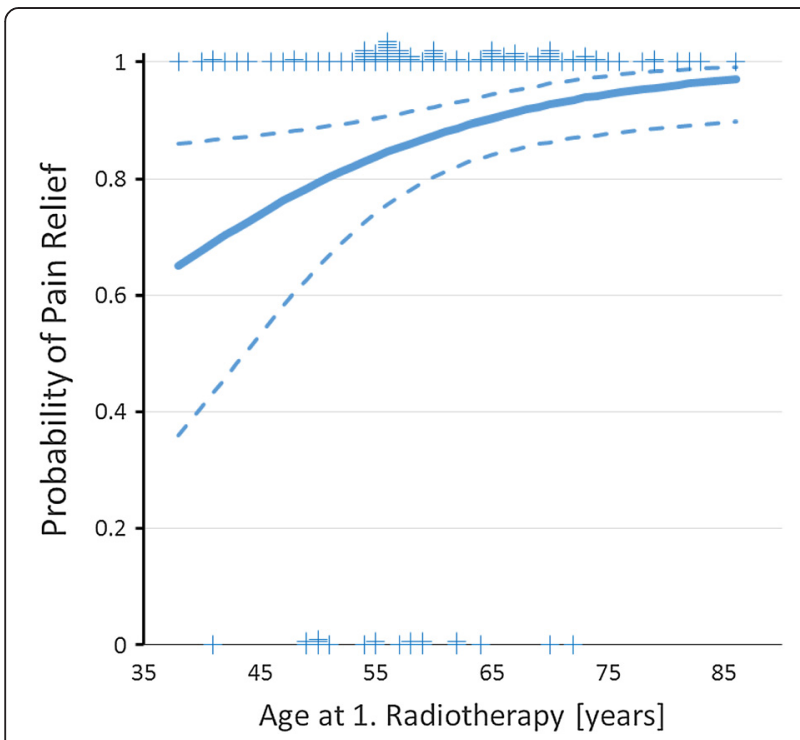

Figure 2 Binary logistic regression analysis of age at 1 st. radiotherapy on pain relief $(\alpha / \beta=10 \mathrm{~Gy}, p=\mathbf{0 . 0 1 4}$. Dotted lines indicate the $95 \%$ confidence limits of the regression line. Tick marks indicate the number of events ( 0 or 1 ) at the respective dose. understood. Since ionizing irradiation induces apoptosis in myeloma cells within $72 \mathrm{~h}$ [16], rapid death of myeloma cells resulting in decompression of nerves and pressure sensors following tumor shrinkage is probably the most important mechanism. Other proposed mechanisms include the obstruction of the secretion of mediators such as substance $\mathrm{P}$ and cytokines, at the interface of myeloma cells and the bone matrix $[17,18]$. Recalcification is achieved long term after a few months, while an analgesic effect is obtained during or immediately after radiotherapy.

The analgesic success rate of radiotherapy in our study was $85 \%$ of all irradiations. In the period of aftercare, $54 \%$ of our patients achieved partial analgesic effect and $31 \%$ achieved complete pain relief. Even partial pain relief is appropriate in view of the few side effects of radiotherapy. Uni- and multivariate logistic regression analysis revealed significant better pain relief at increased ( $2 \mathrm{~Gy}$ equivalence) total dose $(\alpha / \beta=10 \mathrm{~Gy}$, Figure 1) and with increasing age at time of radiotherapy (Figure 2). Using a $\alpha / \beta$ of 10 Gy to calculate 2 Gy equivalent total doses resulted in steeper dose response curves than using a $\alpha / \beta$ of 2 Gy for calculation indirectly indicating that pain relief behaves radiobiologically like an acute effect.

The high efficacy of radiotherapy that induces complete or partial pain relief in $75-95 \%$ of patients with painful myeloma bone lesions has been reported from several independent retrospective evaluations $[7,19,20]$. The majority of the patients in these investigations were treated with total doses between 30 and 40 Gy, typically using fraction sizes between 2 and 3 Gy. Relatively few patients were treated with low doses like $1 \times 8$ Gy or $5 \times 4$ Gy. With a few exceptions, investigators did not test whether greater radiation doses are associated with improved pain control, either because of too small variation in the employed radiation schedules or because of too short variation in pain control. Stölting et al. found in a univariate analysis significantly better pain control for total doses between 40-49.9 Gy compared to total doses below $30 \mathrm{~Gy}$ as well as for doses per fraction of 2 Gy compared to doses per fraction of $\geq 4$ Gy. In the multivariate analysis, only the use of 2 Gy per fraction compared to doses per fraction of $\geq 4$ Gy remained significant. Since 2 Gy per fraction schedules were highly associated with total doses of 40 Gy or greater, the reported results can be interpreted as evidence for a significant dose response relationship. Unfortunately, the authors did not normalize their different fractionation schedule by using 2 Gy equivalent dose or normalized total doses, making a direct comparison to the data presented here difficult. Leigh et al. [21] reported a slight trend to higher rates of pain relief at higher radiation doses, but did also not employ a normalization of the used fractionation schedule. In the work of Adamietz 
Table 4 Analgesic effect and remineralization of patients undergoing radiotherapy

\begin{tabular}{|c|c|c|c|c|c|}
\hline & \multirow[b]{3}{*}{ Simultaneous Chemotherapy } & & \multirow{3}{*}{$\begin{array}{l}\text { All } \\
\mathbf{n} \\
73\end{array}$} & \multirow{2}{*}{\multicolumn{2}{|c|}{$\begin{array}{l}\text { Effective } \\
\text { Treatment } \\
\mathrm{n} \%\end{array}$}} \\
\hline & & & & & \\
\hline \multirow[t]{4}{*}{ Analgesia } & & Yes & & 64 & $87.7 \%$ \\
\hline & & No & 66 & 55 & $83.3 \%$ \\
\hline & Surgical Intervention & Yes & 20 & 16 & $80.0 \%$ \\
\hline & & No & 119 & 103 & $86.6 \%$ \\
\hline \multirow[t]{4}{*}{ Remineralization } & Simultaneous Chemotherapy & Yes & 65 & 29 & $44.6 \%$ \\
\hline & & No & 44 & 26 & $59.1 \%$ \\
\hline & Surgical & Yes & 19 & 07 & $36.8 \%$ \\
\hline & Intervention & No & 90 & 48 & $53.3 \%$ \\
\hline
\end{tabular}

$\mathrm{n}=$ number of patients.

et al. [8] the median total radiation doses (not normalized) of responding and not responding myeloma patients in terms of pain relief were identical, indirectly indicating no distinct dose response relationship. Whether the use of normalized total doses and more advanced statistical tools would have led to the detection of significant dose response relationships for pain control, however, remains unclear. In view of the retrospective nature of the data presented here and the relatively small number of patients treated with normalized total doses below $20 \mathrm{~Gy}$, the question, which dose and fractionation is most appropriate for painful bone lesions from multiple myeloma remains unresolved. Additionally, all patients included in our analysis received antiosteoclastic drugs such as bisphosphonates as well as

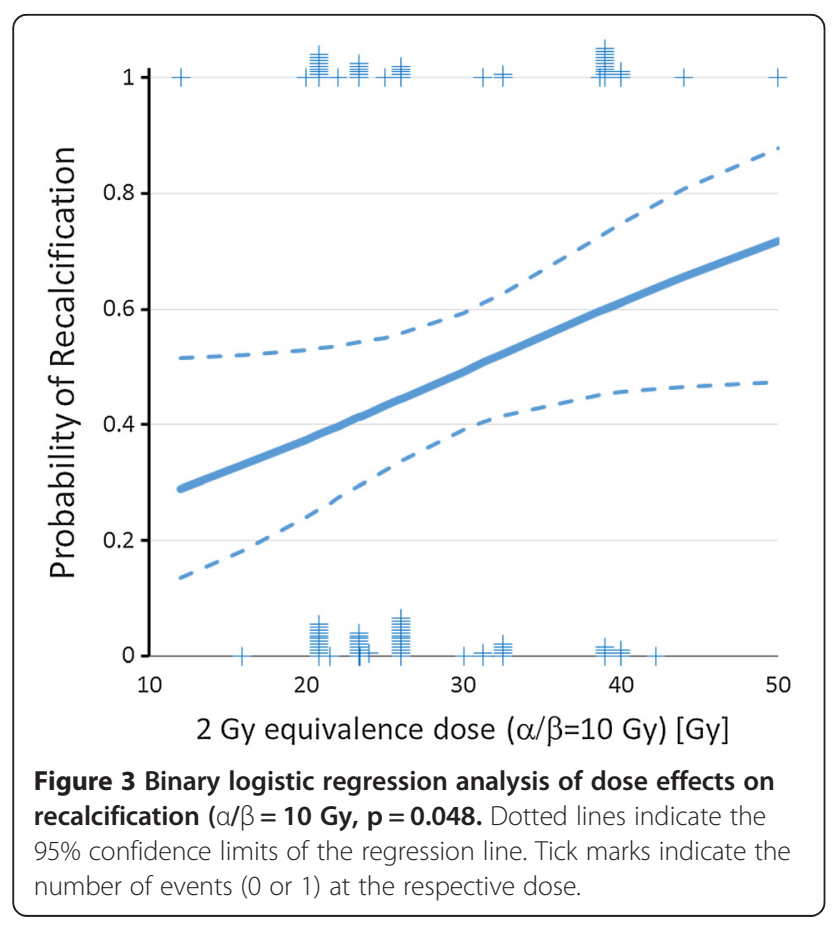



analgetics, if necessary The associated effects of these treatments are difficult to account for given their universal use. In our investigation we found no correlation between pain relief and recalcification. Adamietz et al. [8] reported a significantly longer duration of pain control at higher total radiation doses. No data in this regard are available from other authors.

An unexpected finding was that higher age at radiotherapy was associated with better pain control. This is in contradiction to the results of Stölting et al. [7], who reported better outcome in patients $<60$ years compared to patients $>70$ years. Using the same dichotomous categories instead of age as continuous variable, we found no age effect in our cohort (data not shown). The considerably younger average age in the cohort presents here may explain the different findings that otherwise remain unexplained. Probably the analgesic effect is a summation of the previous treatment, which depends on the biology of the tumor and the prior chemotherapy.

The effect of systemic treatments on pain relief in patients with ostelytic bone lesion has not been well investigated. The shape of the dose response curve for radiotherapy (Figure 1) suggests that approximately 50\% of patients may have the chance to experience pain relief without radiotherapy most likely as result of the effect of systemic treatments. Concurrent systemic therapy at the time of radiotherapy was associated with better pain control in some reports [6]. This association was not confirmed in the present investigation. Since no details on 
concurrent and sequential systemic treatments were reported from any of the analyzed cohorts, potential interaction of radiotherapy with systemic treatments cannot be reliably performed. However, very few severe side effects have been reported, indicating that important interactions of radiotherapy and systemic treatments used for the treatment of multiple myelomas are probably rare.

\section{Recalcification}

Beside pain relief, a recalcification of bony lesions is desirable to reduce the bone fracture rate. Therapy of solitary plasmocytoma underline higher target volume doses are more effective. Total doses of 45 Gy or higher in 2.0-2.5 Gy per fraction seem to eradicate most tumors $[22,23]$ and is re-emphasized by studies of solid tumors [19]. But these clinical trials do not examine multiple myeloma osteolyses in particular.

The recalcification success rate of radiotherapy in our study was $48 \%$ of all irradiations. During follow up, $25 \%$ of our patients achieved partial recalcification and 23\% reached complete recalcification. Uni- and multivariate logistic regression analysis revealed a significant better recalcification at increased ( 2 Gy equivalence) total dose $(\alpha / \beta=10$ Gy, Figure 3$)$, whereas all other tested variables were not predictive for the likelihood of recalcification (Table 4). A limitation of our analysis is that it includes sole radiological reports and/or ROI and diameter measurement of the levels of recalcification, e.g. sclerosis, with the help of radiographs (CT, MRI or conventional $\mathrm{X}$-ray imaging).

Recalcification after radiotherapy has been reported in $11-50 \%$ of patients with bone lesions of solid tumors from several independent retrospective evaluations [6,7]. The majority of the patients in these investigations were treated with total doses between 30 and 50 Gy typically using fraction sizes between 2 and 3 Gy. Relatively few patients were treated with low total doses like $1 \times 8$ Gy or $5 \times 4 \mathrm{~Gy}$, and most studies analyzed osteolyses of diverse solid tumors, not just multiple myeloma patients. There were only few significant results found whether higher radiation doses are associated with improved recalcification for patients with multiple myeloma.

Koswig et al. [19] examined recalcification following radiation therapy with 2 different fractionation schedules $(1 \times 8$ Gy vs $10 \times 3$ Gy $)$ for bone metastasis of solid tumors. The recalcification showed a significant effect concerning patients in the fractionated group $\mathrm{p}<0.0001$ ). In myeloma patients, Stölting et al. [7] found in a univariate analysis significant better recalcification for total doses of 50-60 Gy compared to total doses below 30 Gy. This association remained significant in the multivariate analysis. Further significant parameters for recalcification in the multivariate analysis were concurrent chemotherapy vs no chemotherapy, and no fractures vs fractures. The reported results can be interpreted as evidence for a significant dose response relationship. Unfortunately, the authors did not normalize total doses, making a direct comparison to the data presented here difficult. Balducci et al. [5] described recalcification in patients with osteolytic lesions due to diverse plasma cell neoplasm in 50\% and identified as complete remission in $38 \%$. Mose et al. [6] also found a relevant effect in concurrent chemotherapy, but no difference in recalcification in terms of radiation dose probably due to the low variability in total doses (30-36 Gy) (Table 5). In summary, available data indicate that higher radiation doses result in improved recalcification.

\section{Side effects}

Radiotherapy offers the advantage of few side effects and therefore is an appropriate palliative procedure for treating multiple myeloma [24,25]. Our analysis found 37\% side effects with $50 \%$ grade 1 , and $47.2 \%$ grade 2 . One patient suffered from dysphagia (grade 3). A substantial increase in the side effects with simultaneous chemotherapy has not been reported. We found no correlation between radiotherapy-associated side effects and overall survival. Corresponding to us Foro and Arnalot [20] reported acute side effects in 18\% and Balducci et al. [5] identified $44 \%$ of patients $(n=23)$ with side effects (grade $1-2)$ : hematological toxicity in $11(48 \%)$, gastroenteric

Table 5 Remineralization of osteolysis at different radiation doses in literature

\begin{tabular}{|c|c|c|c|c|c|c|c|}
\hline & $n$ & $\begin{array}{l}\text { Dose (range) } \\
\text { Gy }\end{array}$ & $\begin{array}{l}\text { Radiation } \\
\text { schedule }\end{array}$ & $\begin{array}{l}\text { Remineralization } \\
\%\end{array}$ & $\begin{array}{l}\text { Status idem } \\
\%\end{array}$ & $\begin{array}{l}\text { Progression of } \\
\text { disease } \%\end{array}$ & $\begin{array}{l}\text { Period of } \\
\text { measurement }\end{array}$ \\
\hline Rieden 1986 [26] & 7 & $40-50$ & $5 \times 2 G y$ & 29 & 71 & - & - \\
\hline Weber 1992 [27] & 14 & $30-40$ & $5 \times 2 G y$ & 71 & 29 & - & - \\
\hline Liebross 1998 [28] & 44 & $30-70$ & $5 \times 2 G y$ & 43 & - & - & - \\
\hline Norin 1957 [29] & 53 & $12-48$ & - & 51 & - & - & 1943-1953 \\
\hline Mose 2000 [6] & 56 & $18-45$ & $5 \times 2 G y$ & 46 & 36 & 18 & 1988-1998 \\
\hline Stoelting 2010 [7] & 114 & $2-60$ & $5 \times 2 G y$ & 45 & 49 & 16 & $1970-2003$ \\
\hline Current Data 2014 & 108 & $20-60$ & diverse & 48 & 42 & 10 & 1989-2014 \\
\hline
\end{tabular}

$\mathrm{n}=$ number of patients, Gy = Gray, dose target volume. 
toxicity in $6(26 \%)$, pharyngeal toxicity in $2(9 \%)$, and cutaneous toxicity in $4(17 \%)$ patients. Mose et al. reported about $54 \%$ side effect mostly grade $1-2$; in $4 \%$ Grade 3 (hematopoietic changes, mucositis, creatinine level).

Median overall survival was 89.1 months for the whole cohort and radiation therapy statistically did not have an impact on survival.

\section{Conclusion}

Palliative radiotherapy in plasma cell neoplasm's mostly results in pain relief without significant toxicity. Our data indicate that higher total doses (30-36 Gy) are associated with improved pain relief. The analgesic effect of radiotherapy in myeloma patients appears to be less pronounced younger patients, indirectly indicating that higher radiation doses are especially beneficial in these patients. The likelihood of recalcification after radiotherapy is also increased at higher total radiation doses suggesting that higher doses ( $>40$ Gy) should be considered, if recalcification is thought to be mandatory to lower the risk of fracture.

\section{Competing interests}

The authors declare that they have no competing interests.

\section{Authors' contribution}

This work is a part of the thesis from Thomas A Ochtrop. TO carried out the retrospective studies and drafted the manuscript. TO, CM and EB participated in the design of the study and KK performed the statistical analysis. WB, UG, RF, SG, PG, JH and $\mathrm{KO}$ conceived of the study, and participated in its design and coordination and helped to draft the manuscript. All authors read and approved the final manuscript.

\section{Acknowledgements}

This work was presented at the Radiology Society of North America 2013 meeting in Chicago, Illinois, USA. This work is dedicated to Kim and Thomas Speer who supported our research.

\section{Author details}

${ }^{1}$ Department of Radiation Oncology, Faculty of Medicine,

Heinrich-Heine-University Düsseldorf, Moorenstraße 5, 40225 Düsseldorf, Germany. ${ }^{2}$ Department of Hematology Oncology and Clinical Immunology, Faculty of Medicine, Heinrich-Heine-University Düsseldorf, Dusseldorf, Germany. ${ }^{3}$ Department of Diagnostic and Interventional Radiology, Faculty of Medicine, Heinrich-Heine-University Düsseldorf, Dusseldorf, Germany. ${ }^{4}$ Department of Dermatology, Faculty of Medicine, Heinrich-Heine-University Düsseldorf, Dusseldorf, Germany. ${ }^{5}$ Department of Biostatistics, Johns Hopkins Bloomberg School of Public Health, Baltimore, MD, USA. ${ }^{6}$ Faculty of Diagnostic Radiology, The University of Texas MD Anderson Cancer Center, Houston, Texas, USA. ${ }^{7}$ Department of General, Medical Faculty, Visceral, and Thoracic Surgery, Asklepios Harz Hospitals, Goslar, Germany. ${ }^{8}$ Department of Radiation Oncology, Faculty of Medicine, University of Munich (LMU), Munich, Germany.

Received: 27 October 2014 Accepted: 6 March 2015 Published online: 28 March 2015

\section{References}

1. Usmani SZ, Crowley J, Hoering A, Mitchell A, Waheed S, Nair B, et al. Improvement in long-term outcomes with successive Total Therapy trials for multiple myeloma: are patients now being cured? Leukemia. 2013;27:226-32.

2. Vakaet $L A$, Boterberg T. Pain control by ionizing radiation of bone metastasis. Int J Dev Biol. 2004;48:599-606.
3. Corradini P, Cavo M, Lokhorst H, Martinelli G, Terragna C, Majolino I, et al. Molecular remission after myeloablative allogeneic stem cell transplantation predicts a better relapse-free survival in patients with multiple myeloma. Blood. 2003;102:1927-9.

4. Balducci M, Chiesa S, Manfrida S, Rossi E, Za T, Frascino V, et al. Impact of radiotherapy on pain relief and recalcification in plasma cell neoplasms: long-term experience. Strahlenther Onkol. 2011;187:114-9.

5. Mose S, Pfitzner D, Rahn A, Nierhoff C, Schiemann M, Böttcher HD, et al. Role of radiotherapy in the treatment of multiple myeloma. Strahlenther Onkol. 2000;176:506-12.

6. Stolting $T$, Knauerhase $H$, Klautke $G$, Kundt $G$, Fietkau R. Total and single doses influence the effectiveness of radiotherapy in palliative treatment of plasmacytoma. Strahlenther Onkol. 2008;184:465-72.

7. Adamietz IA, Schober C, Schulte RW, Peest D, Renner K. Palliative radiotherapy in plasma cell myeloma. Radiother Oncol. 1991;20:111-6.

8. Durie BG. The role of anatomic and functional staging in myeloma: description of Durie/Salmon plus staging system. Eur J Cancer. 2006;42:1539-43

9. Norman G. Likert scales, levels of measurement and the "laws" of statistics. Adv Health Sci Educ Theory Pract. 2010;15:625-32.

10. Jordan K, Sanger S: Empfehlungen zur Bewertung der Tumorremission. In Schmoll, Höffken, Possinger (Editors): Kompendium der internistischen Onkologie. Springer Verlag Heidelberg 2006.4.Aufl.,Band 3:p860-865, (ISBN 10 3-540-20657-4)

11. Wang DC. Presentation of treatment results according to 'Reporting Results of Cancer Treatment' recommended by the World Health Organization (WHO), 1981-long term survival of 1,035 cases of nasopharyngeal carcinoma. Zhonghua Zhong Liu Za Zhi. 1985;7:58-61.

12. Lutje S, De Rooy JW, Croockewit S, Koedam E, Oyen WJ, Raymakers RA. Role of radiography, MRI and FDG-PET/CT in diagnosing, staging and therapeutical evaluation of patients with multiple myeloma. Ann Hematol. 2009;88:1161-8

13. Cox JD, Stetz J, Pajak TF. Toxicity criteria of the Radiation Therapy Oncology Group (RTOG) and the European Organization for Research and Treatment of Cancer (EORTC). Int J Radiat Oncol Biol Phys. 1995:31:1341-6.

14. Herrmann TBM, Dörr W. Klinische Strahlenbiologie. München: Urban \& Fischer; 2006. p. 33-6.

15. Perez CA, Brady LW. Principles and Practice of Radioation Oncology (ed 4th reviesed Edition). New York: Lippincott Wiliams \& Wilki; 2004. p. 1053-8.

16. Filippovich IV, Sorokina NI, Robillard N, Lisbona A, Chatal J-F. Radiation-induced apoptosis in human tumor cell lines: adaptive response and split-dose effect. Int J Cancer. 1998;77:76-81.

17. van der Linden YM, Lok JJ, Steenland E, Martijn H, Van Houwelingen $H$, Marijnen CA, et al. Single fraction radiotherapy is efficacious: a further analysis of the Dutch Bone Metastasis Study controlling for the influence of retreatment. Int J Radiat Oncol Biol Phys. 2004;59:528-37.

18. Hoskin PJ. Bisphosphonates and radiation therapy for palliation of metastatic bone disease. Cancer Treat Rev. 2003;29:321-7.

19. Koswig S, Budach V. Remineralization and pain relief in bone metastases after after different radiotherapy fractions (10 times 3 Gy vs. 1 time 8 Gy). A prospective study. Strahlenther Onkol. 1999;175:500-8.

20. Foro Arnalot P, Fontanals AV, Galceran JC, Lynd F, Latiesas XS, De Dios NR, et al. Randomized clinical trial with two palliative radiotherapy regimens in painful bone metastases: $30 \mathrm{~Gy}$ in 10 fractions compared with 8 Gy in single fraction. Radiother Oncol. 2008;89:150-5.

21. Leigh BR, Kurtts TA, Mack CF, Matzner MB, Shimm DS. Radiation therapy for the palliation of multiple myeloma. Int J Radiat Oncol Biol Phys. 1993:25:801-4

22. Hu K, Yahalom J. Radiotherapy in the management of plasma cell tumors. Oncology (Williston Park). 2000;14:101-8. 111; discussion 111-2, 115.

23. Dimopoulos MA, Goldstein J, Fuller L, Delasalle K, Alexanian R. Curability of solitary bone plasmacytoma. J Clin Oncol. 1992;10:587-90.

24. Mill WB, Griffith $R$. The role of radiation therapy in the management of plasma cell tumors. Cancer. 1980;45:647-52.

25. Bosch A, Frias Z. Radiotherapy in the treatment of multiple myeloma. Int J Radiat Oncol Biol Phys. 1988;15:1363-9.

26. Rieden K, Kober B, Mende U, zum Winkel K. Radiotherapy of pathological fractures and skeletal lesions in danger of fractures. Strahlenther Onkol. 1986;162:742-9. 
27. Weber W, Rosler HP, Doll G, Dostert M, Kutzner J, et al. The percutaneous irradiation of osteolytic bone metastases-a course assessment. Strahlenther Onkol. 1992;168:275-80.

28. Liebross RH, Ha CS, Cox JD, Weber D, Delasalle K, Alexanian R, et al. Solitary bone plasmacytoma: outcome and prognostic factors following radiotherapy. Int J Radiat Oncol Biol Phys. 1998:41:1063-7.

29. Norin T. Roentgen treatment of myeloma with special consideration to the dosage. Acta Radiol. 1957:47:46-54.

Submit your next manuscript to BioMed Central and take full advantage of:

- Convenient online submission

- Thorough peer review

- No space constraints or color figure charges

- Immediate publication on acceptance

- Inclusion in PubMed, CAS, Scopus and Google Scholar

- Research which is freely available for redistribution 